\title{
вмJ Global Health Problematic problem diagnostics: why digital health interventions for community health workers do not always achieve their desired impact
}

\author{
Tom Newton-Lewis (D) , ${ }^{1}$ Priya Nanda ${ }^{2}$
}

To cite: Newton-Lewis T, Nanda P. Problematic problem diagnostics: why digital health interventions for community health workers do not always achieve their desired impact. BMJ Global Health 2021;6:e05942. doi:10.1136/ bmjgh-2021-005942

Handling editor Seye Abimbola

Received 7 April 2021 Accepted 16 May 2021
Check for updates

(C) Author(s) (or their employer(s)) 2021. Re-use permitted under CC BY-NC. No commercial re-use. See rights and permissions. Published by BMJ.

${ }^{1}$ Freelance health systems consultant, Witney, UK ${ }^{2}$ Measurement, Learning, and Evaluation, Bill \& Melinda Gates Foundation India, New Delhi, India

Correspondence to Tom Newton-Lewis; tomnewtonlewis@gmail.com

\section{INTRODUCTION}

The last few years has seen an explosion in digital health interventions, primarily using mobile phones (mHealth), designed to increase the effective coverage and quality of services provided by community health workers (CHWs), ${ }^{1}$ particularly in India.

However, as acknowledged by the recent WHO Guideline: Recommendations on Digital Interventions for Health System Strengthening, the evidence base is weak and needs to be amplified to justify scaling up of digital interventions. ${ }^{2}$ The Cochrane systematic reviews undertaken to inform the WHO guideline showed that 'the available evidence suggested that these types of interventions may make little or no difference to the outcomes that were measured' and 'it is unrealistic to expect consistent positive effects in mobile health programmes'.

In this commentary, from our experience as a producer and commissioner respectively of evidence on CHWs and digital health interventions in India, we argue that the mixed evidence is partially explained by how digital interventions problematise $\mathrm{CHWs}$ and are often built on implicit-and misplacedassumptions that the constraints to performance can be solved at the level of the CHW rather than the system that they are part of.

\section{HOW PROBLEM DIAGNOSTICS PROBLEMATISE CHWS}

While digital tools cover the whole range of healthcare provider interventions as classified by the WHO, ${ }^{4}$ many focus on supporting the performance of individual CHWs in delivering routine services, particularly through job aids that assist scheduling and activity planning, provide decision support, and include audiovisual materials that can be used to augment

\section{Summary}

Despite a proliferation of digital health interventions designed to support the improved coverage and quality of community health worker services in India, few have achieved significant impact at scale.

- Most interventions target the individual worker-particularly through job aids-and therefore implicitly, and often incorrectly, assume that the constraints to performance are within the control of the worker, rather than systemic and structural.

- Digital interventions need to be designed to be sensitive to the needs and systemic predicaments of community health workers through approaches that genuinely engage them in design, understand the influence of the intangible norms and scripts that shape their everyday work lives, and allow local adaptation and experimentation to succeed at scale.

- Digital interventions are not a one-off singular solution and, to have more than marginal impact, need to work complementary to, rather than direct attention away from, the larger, more complex system reforms that are required to give community health workers the opportunity to deliver services and build trusting relationships with communities.

CHW-community interactions. Many of these rely on the inputting of client data that would traditionally be done on paper registers.

There is clearly an important role for these interventions, for example given the high workloads for manual data reporting, low levels of technical knowledge and skills of $\mathrm{CHWs},{ }^{5}$ and challenges of delivering quality in-service training at scale. For example, the mobile phone-based job aid known as the Information Communication TechnologyContinuum of Care Service (ICT-CCS) piloted in Bihar improved the self-reported skills of Accredited Social Health Activists (ASHAs) ${ }^{6}$

However, that these interventions target the performance of CHWs as individuals in the system and not as part of a network of 
actors and processes surfaces their implicit assumption that CHWs have complete agency over the coverage and quality of services they deliver. Recent work, applying a diagnostic framework of means, motives and opportunity, shows that the constraints to performance are often primarily outside of the CHW's control, and instead are structural and systemic, ${ }^{5}$ including factors such as workload, excessive reporting requirements, access to resources, and community preferences. In these situations, the effectiveness of interventions designed to target individual workers' performance devoid of contextually relevant structural changes would be inherently limited.

For example, in India, there has been much interest in increasing the low effective coverage of home visits to newborns by ASHAs. The ICT-CCS included automated scheduling of home visits. However, an evaluation found no significant difference between the number of home visits received by mothers of children aged $2-4$ weeks in treatment and control groups, and a small difference in the first week. ${ }^{6}$ In a separate study, the authors report that the main constraints to home visits were concerns about safety when travelling within the community, the temporary migration of mothers to their maternal homes during childbirth, and unrealistic workloads, limiting the potential effectiveness of job aids. ${ }^{7}$ Studies of other CHW cadres in India have similarly identified how performance constraints are systemic or structural and thus mainly outside of the control of the worker. ${ }^{8}$

\section{IMPLICATIONS}

The risk, therefore, is that digital CHW interventions target the service delivery symptoms of underlying systemic challenges, and that this narrow construction of the problems facing CHWs limits intervention effectiveness. Rather, digital interventions need to be designed to be sensitive to the needs and predicaments of CHWs, grounded in complex systems thinking. Expanding this proposition, we identify four points for consideration by those designing future interventions.

\section{Engage CHWs and community members in the design process}

Interventions need to be fully cognisant of the complex lived realities of users. Given how hard this is for outside observers to understand, this requires CHWs and community members to be part of teams designing, implementing and evaluating digital interventions. This has been acknowledged by WHO. ${ }^{9}$ Yet we see little evidence that the multiplicity of digital health interventions in India are based on genuine user engagement. Too often, digital health interventions are done 'to' CHWs, based on a perceived understanding of their challenges-which, as we have seen, is often misguided. This often causes digital interventions to create additional workloads, with digital data systems running parallel to the paper-based systems they are intended to replace. ${ }^{3}$ Moreover, the lack of genuine user involvement replicates and exacerbates the low positionality of CHWs, reflective of their limited power within the system. As most CHWs are women, the experience of power asymmetries is highly gendered. For example, women are often positioned as beneficiaries of digital interventions without having opportunities to shape such projects to better fit their needs. ${ }^{10}$

\section{Give due consideration to positioning CHWs as trustworthy and credible connectors with the community}

Recent advances in thinking about CHWs situates them at the interface between complex health systems and complex communities, both of which are heavily influenced by 'intangible software'-socially constructed shared norms, values and beliefs. ${ }^{11}{ }^{12}$ CHWs need to develop strong, trust-based relationships to navigate this positioning. Digital interventions influence this intangible software as they fundamentally alter how CHWs and community members interact, and this needs to be fully considered by intervention designers.

The Cochrane systematic review on health workers' perceptions and experiences of mHealth technologies shows how interventions can have positive and negative effects on intangible software. ${ }^{3}$ For example, being custodians of expensive equipment can raise the perceived status of a CHW, and playing videos of behavioural change messages can lend credibility. $88 \%$ of ASHAs reported increased trust from village members after using an mHealth intervention. ${ }^{13}$ On the flip slide, job aids can make worker-beneficiary interactions impersonalised, can cause embarrassment if workers make mistakes in front of clients, can be disempowering for CHWs with low digital literacy, and can reduce the quality of interactions if the technology is cumbersome or not tailored to the local language. For example, a study found that, despite village level Anganwadi workers reporting that the Common Application Software they were using gave their messages legitimacy, it was found to risk making interactions shorter and perfunctory, replacing rather than strengthening interpersonal communication. ${ }^{14}$ The intervention was not sufficient to overcome low levels of trust between the CHWs and community members.

\section{Acknowledge complexity and its implications}

The literature on complex systems argues that, given contextual constraints are so interlinked and interdependent, isolated targeted interventions are guaranteed to only have marginal impact. Yet the urgency to address problems often gives primacy to time bound, stand-alone interventions suitable for external facilitation designed to deliver linear, measurable impact and that meet the criteria for interventions to be 'novel' and 'innovative', concepts often prioritised this last decade of development assistance. Very few interventions are designed with understanding of asymmetries of power, accountability, and the relationships that exist in any health system organisation. Eschewing this understanding, interventions avoid the messy, complex support to internal system actors required to influence system behaviour. Digital interventions need to engage with this complexity. For 
example, in other contexts, mobile communication has been used to facilitate more flexible and supportive supervision of $\mathrm{CHWs}^{15}$ rather than target specific service delivery outcomes.

\section{Understand that scale requires adaptability}

Digital interventions provide the allure of scalability but few of the pilot digital health initiatives that have emerged over the last decade have reached sustained delivery at scale. ${ }^{1}$ Challenges with integration into, and interoperability with, government systems, and practical constraints with replacing and updating software are well documented. More fundamentally, the community health systems literature identifies the limitations of scaling one-size-fits-all interventions into complex and heterogeneous communities. ${ }^{12}$ Rather, many problems require experimentation and learning about what works to address specific problems in a particular context. Digital interventions need to facilitate, and not constrain, local adaptation. For example, this requires ensuring that data is put in the hands of users in an actionable and interpretable way to trigger sensemaking, rather than just be pushed upwards to supervisors, as happens with many existing initiatives.

\section{CONCLUSION}

There is an appropriate role for digital health interventions in supporting CHWs in India, particularly targeting technical knowledge and skills. However, this must happen alongside, and not redirect attention away from the larger, more complex system reforms required to give CHWs the opportunity to deliver services and build trusting relationships with communities. Without this more fundamental reform, digital health interventions are likely to continue to have the marginal average impact documented in systematic reviews. We recommend the need to better adopt the implications of the complex systems literature and considerations of intangible software through human centred design methods and more grounded problem diagnostics.

Contributors TN-L and PN equally contributed to the conceptualisation, writing and finalisation of this commentary.

Funding This work is partly funded through a health systems learning grant from the Bill and Melinda Gates Foundation INV-007989

Competing interests None declared.

Patient consent for publication Not required.

Provenance and peer review Not commissioned; internally peer reviewed.
Data availability statement This commentary does not report on independent research. Data is available from the individual references.

Open access This is an open access article distributed in accordance with the Creative Commons Attribution Non Commercial (CC BY-NC 4.0) license, which permits others to distribute, remix, adapt, build upon this work non-commercially, and license their derivative works on different terms, provided the original work is properly cited, appropriate credit is given, any changes made indicated, and the use is non-commercial. See: http://creativecommons.org/licenses/by-nc/4.0/.

\section{ORCID iD}

Tom Newton-Lewis http://orcid.org/0000-0002-8488-5226

\section{REFERENCES}

1 George A, LeFevre A, Ved R. Taming the wild West of digital health innovation. Project Syndicate, 2019.

2 World Health Organisation. WHO Guideline. Recommendations on digital interventions for health system strengthening, 2019. Available: http://apps.who.int/iris/bitstream/

3 Odendaal WA, Anstey Watkins J, Leon N, et al. Health workers' perceptions and experiences of using mHealth technologies to deliver primary healthcare services: a qualitative evidence synthesis. Cochrane Database Syst Rev 2020;15.

4 World Health Organisation. Classification of digital health interventions. Geneva: World Health Organization, 2018.

5 John A, Newton-Lewis T, Srinivasan S. Means, motives and opportunity: determinants of community health worker performance. BMJ Glob Health 2019;4:e001790.

6 Carmichael SL, Mehta K, Srikantiah S, et al. Use of mobile technology by frontline health workers to promote reproductive, maternal, newborn and child health and nutrition: a cluster randomized controlled trial in Bihar, India. $J$ Glob Health 2019;9:0204249.

7 Oxford Policy Management. The Norway-India partnership initiative phase II: impact evaluation of five interventions. Delhi, 2018.

8 John A, Nisbett N, Barnett I, et al. Factors influencing the performance of community health workers: a qualitative study of Anganwadi workers from Bihar, India. PLoS One 2020;15:e0242460.

9 World Health Organisation. Report of the consultation meeting on digital health interventions and health workforce capacity building, 2019.

10 George AS, Morgan R, Larson E, et al. Gender dynamics in digital health: overcoming blind spots and biases to seize opportunities and responsibilities for transformative health systems. J Public Health 2018;40:ii6-11.

11 Kok MC, Broerse JEW, Theobald S, et al. Performance of community health workers: situating their intermediary position within complex adaptive health systems. Hum Resour Health 2017;15:59.

12 George AS, LeFevre AE, Schleiff M, et al. Hubris, humility and humanity: expanding evidence approaches for improving and sustaining community health programmes. BMJ Glob Health 2018;3:e000811.

13 Ilozumba O, Dieleman M, Kraamwinkel N, et al. "I am not telling. The mobile is telling": Factors influencing the outcomes of a community health worker mHealth intervention in India. PLOS One 2018;13:e0194927.

14 Gopalakrishnan L, Buback L, Fernald L, et al. Using mHealth to improve health care delivery in India: a qualitative examination of the perspectives of community health workers and beneficiaries. PLOS One 2020;15:e0227451.

15 Henry JV, Winters N, Lakati A, et al. Enhancing the supervision of community health workers with WhatsApp mobile messaging: qualitative findings from 2 low-resource settings in Kenya. Glob Health Sci Pract 2016;4:311-25. 